\title{
Kinetics of Reduction of Copper Oxide from Liquid Slag Using Carbon
}

\author{
R. G. Reddy ${ }^{* 1}$, V. L. Prabhu ${ }^{2}$ and D. Mantha ${ }^{3}$ \\ ${ }^{1}$ ACIPCO Professor, ${ }^{2}$ Graduate Student and ${ }^{3}$ Research Associate \\ Department of Metallurgical and Materials Engineering \\ P. O. Box 870202, The University of Alabama \\ Tuscaloosa, AL 35487-0202, U. S. A.
}

(Received March 18, 2003: final form April 20, 2003)

\begin{abstract}
Recent trends in oxidative continuous smelting of copper concentrates are leading to higher copper loss in slag (up to $6 \%$ ) mostly in the form of copper oxide. Reduction of copper oxide from slag is further carried out in slag cleaning furnace with carbon as reductant. In the present study, reduction of copper oxide from a liquid slag by carbon was investigated. The experiments were carried out in a resistance heating furnace using a graphite lined alumina crucible. The influence of various parameters such as temperature, initial $\mathrm{CuO}_{0.5}$ content in the slag, and stirring of the melt by argon, on the reduction kinetics of $\mathrm{CuO}_{0.5}$ was studied. Based on the results obtained from this investigation the probable rate controlling mechanism was proposed. Results suggest that the reduction reaction was first order with respect to the concentration of $\mathrm{CuO}_{0.5}$ and was controlled by chemical reaction at the slag/graphite interface. Activation energy for the reduction of $\mathrm{CuO}_{0.5}$ by carbon was estimated to be $188.4 \mathrm{~kJ} / \mathrm{mol}$, which is comparable with the activation energy of the catalyzed Boudouard reaction.
\end{abstract}

\section{INTRODUCTION}

The recent trend in the world copper smelting follows the extensive use of oxygen to increase the copper grade in matte thereby enabling a highly efficient and environmentally acceptable smelting process. However, increase in the copper grade of matte has several drawbacks, such as: copper loss in slag, difficulty in impurity control, and refractory damage. It has been shown $/ 1 /$ that when the copper grade of matte exceeds $70 \%$, the oxygen potential in the slag-metal system increases drastically leading to copper loss to the slag predominantly in the form of oxidic copper. Hence the recent trends of continuous copper smelting invariably lead to significant copper loss in slag (up to $6 \%$, which needs to be recovered by means of reduction in a separate slag cleaning furnace.

Reduction of oxides from slags by carbon reductant in the form of dissolved carbon in iron or graphite has been studied by a large number of researchers. Extensive research was conducted in the reduction of iron oxide $/ 2-5 /$ and silica $/ 6 /$ from liquid slag by carbon or carbon dissolved in iron. A number of studies were performed on recovery of metal values from copper smelting slags /7-9/. However, little information is available in literature concerning the reduction kinetics of copper oxide by carbon from non-ferrous slags. From an industrial point of view, knowledge of the slagreductant reactions and the rate controlling mechanisms are important for the optimizing process parameters in a copper smelting process.

\footnotetext{
" Corresponding Author
} 
The purpose of the present investigation is to study the kinetics of reduction of $\mathrm{CuO}_{0.5}$ from a non-ferrous synthetic slag which is similar to the industrial continuous converter slag and to determine the rate controlling mechanism of the reduction process.

Reduction of copper oxide by carbon from synthetically prepared slags having composition similar to that of the industrial copper slag was studied. The effect of various parameters such as temperature, stirring of the oxide melt on the rate of reduction was studied and the probable rate controlling mechanism was determined.

\section{EXPERIMENTAL}

In studies involving recovery of metal values from non-ferrous slags the slag is intimately mixed with carbon and reduction takes place in molten conditions. Reaction scheme of this kind is not suitable to investigate kinetics of reduction due to the uncertainty of slag/reductant interfacial area and its variation during the course of reaction. Reduction of an oxide from a slag by dissolved carbon resolves the uncertainty of interfacial area. Hence, most of the studies on reduction kinetics of oxides from slags were conducted using carbon dissolved in iron as the reducing agent.

However, in the case of reduction of copper oxide from non-ferrous slags with carbon dissolved in iron there is an inherent difficulty due to the presence of two reducing agents (iron and carbon) in the reduction process. Thus the reducing agent has to be in the form of graphite in contact with the molten slag for the reduction of copper oxide from non-ferrous slag systems.

In order to generate meaningful kinetic data, laboratory studies are designed to maintain a constant slag/reductant contact area. There are several ways of establishing the constant area of contact between the reducing agent (carbon) and the slag. Placing a graphite disc on top of the melt or bottom would not solve the problem because carbon gets depleted leaving a difference in the surface area and may not stay in the position during the course of the experiment. The graphite disc would also hinder the sampling of slag at regular intervals. Hence it was decided to have a annular graphite tube fitted exactly into an alumina crucible so that the reaction takes place towards the sides of the crucible and allows for slag sampling as well as copper to be deposited at the bottom of the crucible.

Technical grade $\mathrm{CaO}, \mathrm{SiO}_{2}, \mathrm{Al}_{2} \mathrm{O}_{3}, \mathrm{Fe}_{2} \mathrm{O}_{3}$ and $\mathrm{Fe}$ were melted in a recrystallized alumina crucible for two hours at $1573 \mathrm{~K}$. To the molten mixture of the above oxides a known amount of $\mathrm{Cu}_{2} \mathrm{O}$ was added in the form of a pellet and the melt was allowed to homogenize. The composition of the slag was prepared so as to simulate the industrial slag. The homogenized slag was cooled, crushed, ground and made into pellets. The slag composition (wt \%) was $1.625 \% \mathrm{CuO}_{0.5}, 33.97 \% \mathrm{FeO}$, $6.34 \% \mathrm{Fe}_{2} \mathrm{O}_{3}, 29.5 \% \mathrm{SiO}_{2}, 18.0 \% \mathrm{CaO}$ and $8.94 \%$ $\mathrm{Al}_{2} \mathrm{O}_{3}$.

Figures 1(a) and (b) show the schematic diagrams of the experimental setup and the alumina crucible assembly used in this investigation. The water cooled furnace was resistance heated and the furnace chamber was made of mullite tube. Experiments were conducted in an alumina crucible of $200 \mathrm{ml}$ capacity. A graphite cylinder of thickness $6.35 \mathrm{~mm}\left(0.25^{\prime \prime}\right)$ was fitted tightly into the alumina crucible. Slag weighing $100 \mathrm{~g}$ was taken into the crucible and was placed carefully inside

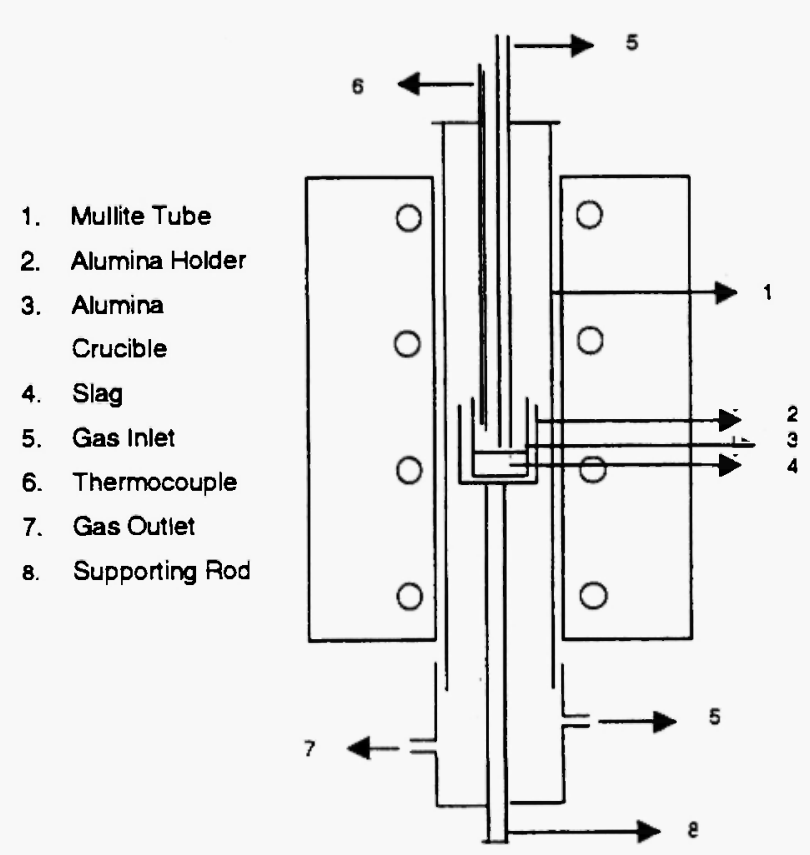

Fig. 1(a): Schematic Diagram of the Experimental Setup 


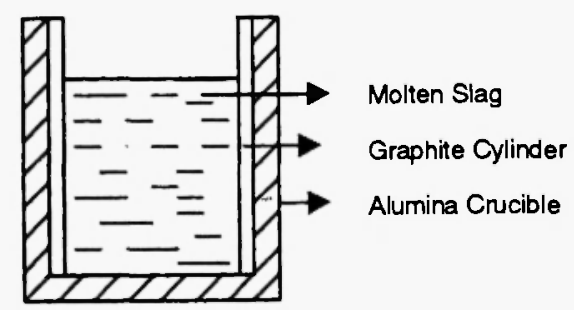

Fig. 1(b): Schematic Diagram of the Alumina Crucible used for the Experiments

the furnace on a pedestal or the crucible holder held firmly by a supporting rod from the bottom of the furnace assembly. The temperature of the melt was measured by means of a $\mathrm{Pt}-\mathrm{Pt} / 10 \% \mathrm{Rh}$ thermocouple placed from the top of the furnace assembly. The reduction essentially took place along the circumference of the alumina crucible fitted with the graphite cylinder and the reduced copper was allowed to settle to the bottom of the crucible without hindering the progress of the reaction. Experiments were conducted in purified argon atmosphere.

At selected time intervals, slag samples were taken out by dipping a steel rod into the melt from the top. Each sample was.crushed and ground using a ceramic mortar. Any residual metal particles were removed using a hand magnet.e The slag samples were then analyzed for copper by an Atomic Absorption Spectrometer (AAS).

\section{RESULTS}

The results obtained in the present investigation are presented in the order of effect of various parameters such as temperature, stirring of the slag melt and initial concentration of the oxide in the melt. Two reaction models (i) chemical reaction model and (ii) diffusion model have been proposed to evaluate the mechanism of copper oxide reduction by carbon in the present experimental setup. The experimental data obtained in the study have been fitted to both models and the possible reaction mechanism was estimated. Further, the activation energies of the two processes were evaluated and compared with those available in the literature for the suggested reaction mechanism. The reasons for the possible reaction mechanism suggested in this work are also discussed.

\section{A. Effect of Temperature}

Figure 2 shows the reduction of copper oxide from the slag as a function of time at three temperatures of this study. At any given temperature, the reduction was rapid in the initial stages followed by a plateau region. The plateau region indicates the equilibrium concentration of $\mathrm{CuO}_{0.5}$ in the bulk of the slag phase at a given temperature. The rate of reduction increased with increase in temperature. For example, after 10 minutes of the reaction the amount of $\mathrm{CuO}_{0.5}$ in the slag was about $0.2 \%$ at $1598 \mathrm{~K}$ compared to $0.6 \%$ at $1513 \mathrm{~K}$. The effect of temperature was more pronounced during the early stages of reduction. First order reaction kinetics with respect to $w t \%$ of $\mathrm{CuO}_{0.5}$ was observed during the initial period of reaction for all the temperatures of this investigation.

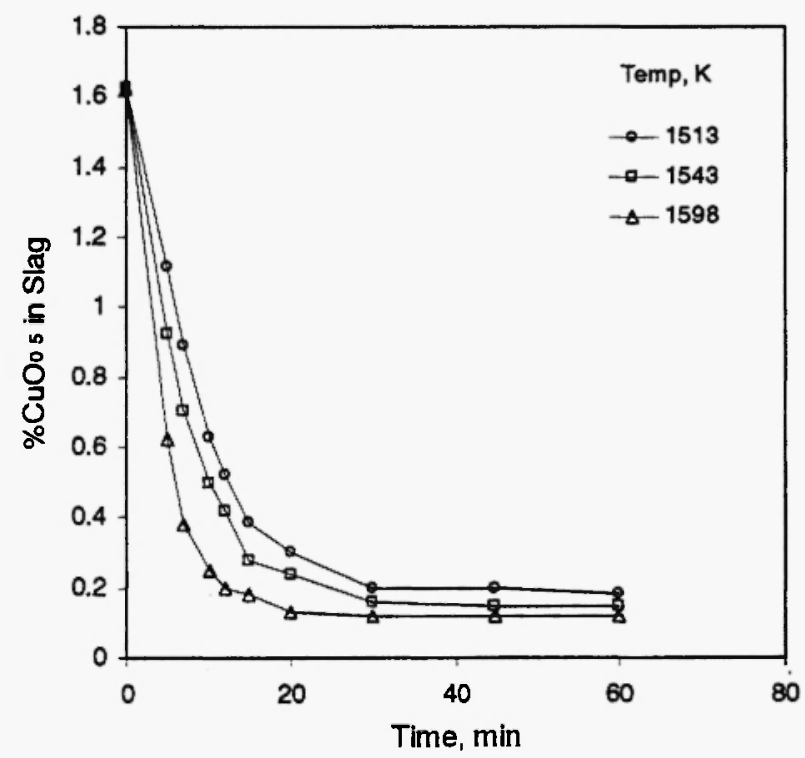

Fig. 2: Variation of $\% \mathrm{CuO}_{0.5}$ in slag as a function of time at different temperatures

\section{B. Effect of Stirring the Melt}

Experiments were conducted under a continuous flow of argon to study the effect of stirring of the melt on the kinetics of $\mathrm{CuO}_{0.5}$ reduction by carbon. Figure 3 


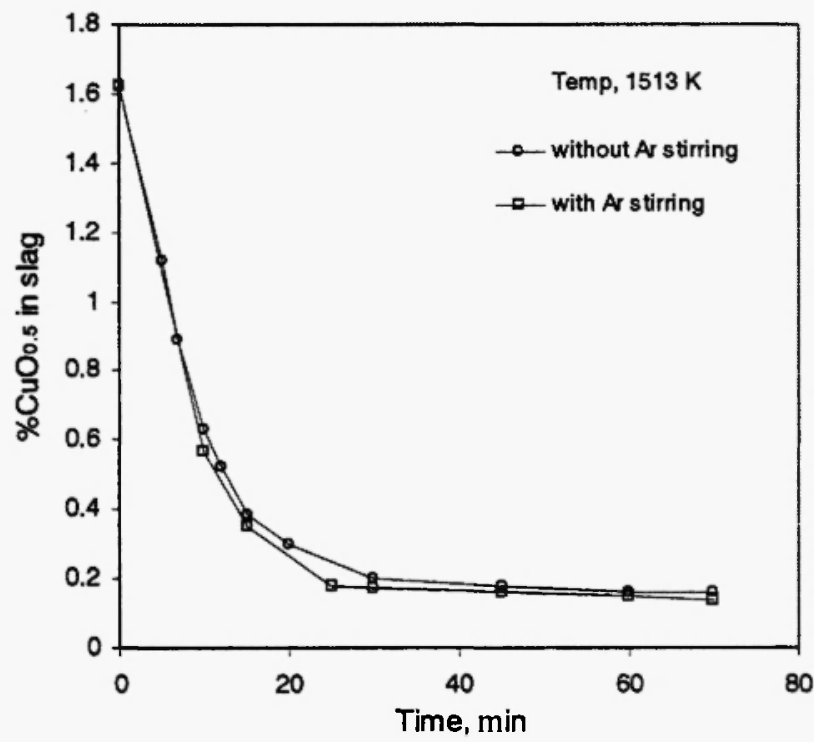

Fig. 3: Effect of argon gas stirring on the reduction of copper oxide at $1513 \mathrm{~K}$

shows the plot of the variation of wt $\% \mathrm{CuO}_{0.5}$ as a function of time with and without flowing argon at 1513 $K$. It can be seen from the figure that at about 20 minutes the amount of copper oxide remaining in the slag is very low $(<0.2 \%)$. It can also be seen that, within experimental errors, stirring the slag melt did not affect the reduction kinetics. The rates of diffusion controlled reactions would typically increase with increase in melt stirring. Although there was stirring of the melt by $\mathrm{CO}$ generated during the reduction process, the results in Fig. 3 indicate clearly that the rate controlling step in the reduction of $\mathrm{CuO}_{0.5}$ by carbon in the present study was not diffusion but the slag phase.

\section{Effect of Initial Concentration}

Figure 4 shows the variation of $\mathrm{wt}^{2} \% \mathrm{CuO}_{0.5}$ in the slag as a function of time at $1513 \mathrm{~K}$ for two different initial concentrations of copper oxide ( $1.63 \mathrm{wt} \%$ and 8.0 $w t \%)$ in the slag. It can also be seen that within about 40 minutes the copper content in both the slags was reduced to below $0.1 \mathrm{wt} \%$. The slopes of the two curves corresponding to initial copper oxide content of $1.63 \%$ and $8.0 \%$ of $\mathrm{CuO}_{0.5}$ are 0.094 and 0.084 respectively. It can be seen that the slopes are identical within the experimental errors. Hence, it can be stated that initial content of copper oxide did not influence the reduction kinetics.

Theoretical models for chemical reaction and diffusion mechanisms have been developed and the experimental results of this study have been analyzed in order to determine the possible reaction mechanism for the reduction of copper oxide by carbon in the slag melt.

The linear portions of the experimental data in Figs 2 and 4 were modeled using the reaction models which are described in the following sections.

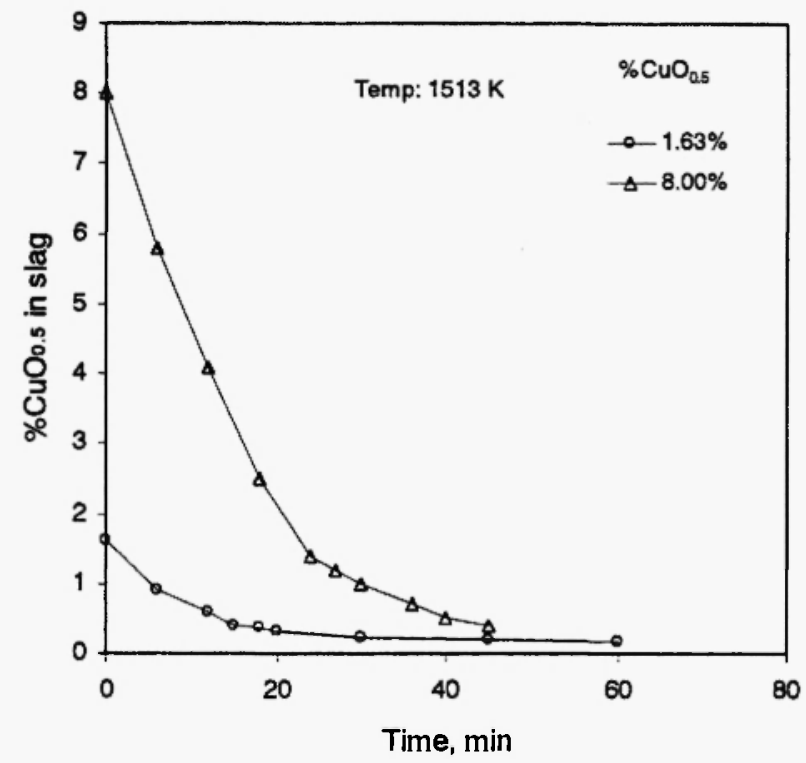

Fig. 4: Variation of $w t \% \mathrm{CuO}_{0.5}$ in slag as a function of time at $1513 \mathrm{~K}$ for slags having two different initial contents of $\mathrm{CuO}_{0.5}$

\section{Reaction Models}

The heterogeneous system in this investigation involves an interaction between three phases, (i) slag, (i) metal and (iii) gas. The reaction kinetics in the present system could involve a number of rate limiting steps, which include transport of reactants in the slag from the bulk interior to the slag/graphite reaction interface, the chemical reaction at the interface and nucleation of the gaseous phases at the reaction site. Two reaction models have been postulated to explain the rate controlling mechanism of copper oxide reduction, namely: (i) chemical reaction model and (ii) diffusion model. The 
development of the two models is explained and mathematical expressions for both models are derived in the following sections.

\section{Chemical Reaction Model}

Reduction of copper oxide from the synthetic slag by carbon takes place at the crucible circumference/slag via the Boudouard reaction interface given by the following equation:

$$
\begin{aligned}
& \mathrm{CuO}_{0.5}(\mathrm{sl})+\frac{1}{2} \mathrm{CO}(\mathrm{g})=\mathrm{Cu}(\mathrm{m})+\frac{1}{2} \mathrm{CO}_{2}(\mathrm{~g}) \\
& \mathrm{C}(\mathrm{s})+\mathrm{CO}_{2}(\mathrm{~g})=2 \mathrm{CO}(\mathrm{g})
\end{aligned}
$$

where the reaction assuming first order kinetics with respect to the $w t \%$ of reactant species, $\mathrm{CuO}_{0.5}$, the rate of reduction reaction (1) is given by:

$$
\begin{gathered}
-\left(\frac{\mathrm{d} \% \mathrm{CuO}_{0.5}}{\mathrm{dt}}\right)=\mathrm{k}_{1} . \% \mathrm{CuO}_{0.5}(\mathrm{sl})-\mathrm{k}_{2} . \% \mathrm{Cu}(\mathrm{m}) \\
\text { wt } \% . \mathrm{cm}^{-2} \mathrm{sec}^{-1}
\end{gathered}
$$

where $k_{1}$ and $k_{2}$ are the forward and backward reaction rate constants and the symbols in brackets (sl) and (m) refer to the slag and the metal phases respectively. At steady state, the rates of the forward and backward reactions are equal. Hence, we have the following relation:

$$
\mathrm{k}_{1} . \% \mathrm{CuO}_{\partial .5}^{*}(\mathrm{si})=\mathrm{k}_{2} . \% \mathrm{Cu}^{\mathrm{e}}(\mathrm{m})
$$

where the superscript ' $\mathrm{e}$ ' refers to the steady state concentration. Mass balance for copper in the system yields the following relation:

$$
\mathrm{w}_{\mathrm{m}} \cdot \% \mathrm{Cu}^{\mathrm{t}}=\mathrm{f} \cdot \mathrm{W}_{\mathrm{sl}} \cdot\left(\% \mathrm{CuO}_{0.5}^{0}-\% \mathrm{CuO}_{0.5}^{\mathrm{t}}\right)
$$

where $W_{m}, W_{s l}$ and ' $f$ ' are the weight of the metal, weight of the slag, and ratio of the molecular weight of $\mathrm{CuO}_{0.5}$ to the atomic weight of $\mathrm{Cu}$ and the superscripts ' $o$ ' and ' $t$ ' refer to the initial $w t \%$ of copper oxide and the amount present at any time ' $t$ ' respectively.
Substituting the relations for ' $\mathrm{k}_{2}$ ' and $\% \mathrm{Cu}(\mathrm{m})$ in equation (3) we have:

$$
\begin{aligned}
& -\left(\frac{\mathrm{d} \% \mathrm{CuO}_{3.5}^{\prime}}{\mathrm{dt}}\right)= \\
& \mathrm{k}_{1} \cdot\left(\frac{\% \mathrm{CuO}_{05}^{\circ}}{\% \mathrm{CuO}_{35}^{\circ}-\% \mathrm{CuO}_{05}^{\circ}}\right) \cdot\left(\% \mathrm{CuO}_{0.5}^{\prime}-\% \mathrm{CuO}_{5.5}^{\mathrm{e}}\right)
\end{aligned}
$$

Integration of the above equation (6) between the limits ' 0 ' and ' $t$ ' yields the rate constant ' $k_{1}$ ' for the chemical reaction controlled reduction of copper oxide:

$$
\begin{aligned}
& -\ln \left(\frac{\% \mathrm{CuO}_{0.5}^{t}-\% \mathrm{cuO}_{0.5}^{\mathrm{e}}}{\% \mathrm{CuO}_{3.5}^{\circ}-\% \mathrm{CuO}_{0.5}^{\mathrm{e}}}\right)= \\
& \mathrm{k}_{1} \cdot\left(\frac{\% \mathrm{CuO}_{0.5}^{\circ}}{\% \mathrm{CuO}_{0.5}^{\circ}-\% \mathrm{CuO}_{0.5}^{\circ}}\right) \cdot \mathrm{t}
\end{aligned}
$$

Plotting the left hand side expression of equation (7) with respect to time ' $t$ ' yields the rate constant at each temperature of the experiment. Figure 5 shows the linear fit for the chemical reaction controlled reduction of copper oxide given by equation (7).

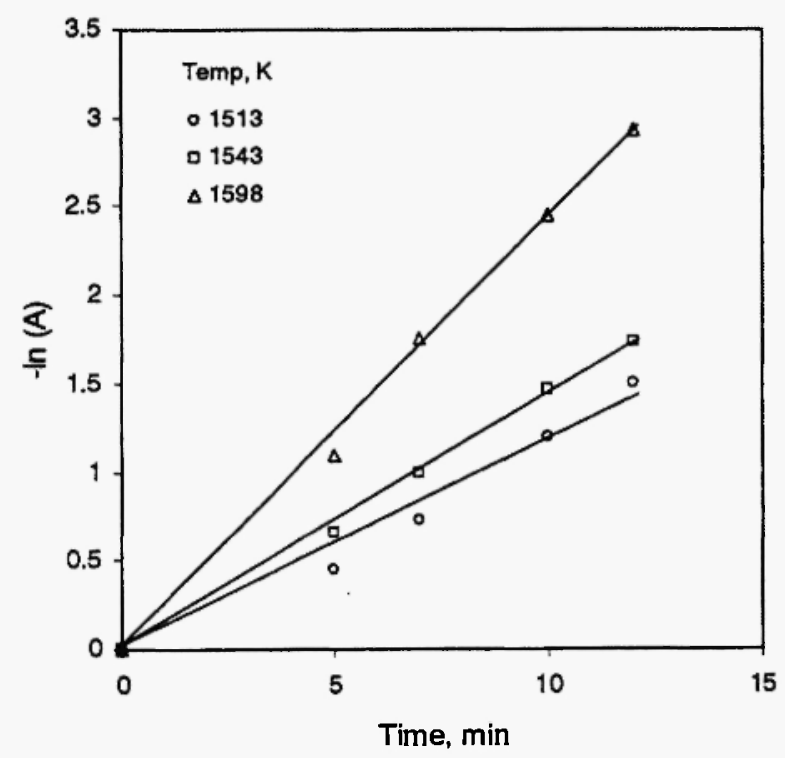

Fig. 5: Plot of the chemical reaction controlled model [Eqn. (6)], where $\mathrm{A}$ is given by $\left(\frac{\% \mathrm{CuO}_{0.5}^{\mathrm{t}}-\% \mathrm{CuO}_{0.5}^{\mathrm{e}}}{\% \mathrm{CuO}_{0.5}^{\mathrm{o}}-\% \mathrm{CuO}_{0.5}^{\mathrm{e}}}\right)$ 


\section{Diffusion Model}

The derivation of a theoretical expression for the diffusion controlled model for the reduction of $\mathrm{CuO}_{0.5}$ is done as follows: The diffusion of $\mathrm{CuO}_{0.5}$ from the bulk of the slag phase to the slag/graphite interface is given by:

$$
\mathrm{J}_{\mathrm{CuO}_{0.5}}=:-\mathrm{k}_{\mathrm{m}} \cdot\left({ }^{\mathrm{C}} \mathrm{CuO}_{0.5}(\mathrm{~b})-\mathrm{C}_{\mathrm{CuO}_{0.5}} \text { (i) }\right)
$$

where $\mathrm{J}_{\mathrm{CuO}_{0}}$ is the molar flux of the oxide, $\mathrm{k}_{\mathrm{m}}$ is the mass transfer coefficient of the oxide and $\mathrm{C}_{\mathrm{CuO}_{05}}$ (b) and $\mathrm{C}_{\mathrm{CuO}_{03}}$ (i) are the concentrations of the oxide in the bulk of the slag and at the reaction interface respectively. If the reaction is controlled by the mass transport of $\mathrm{CuO}_{0.5}$ through the slag phase, the chemical reaction at the slag/graphite interface would be fast enough, so that $\mathrm{CuO}_{05}(\mathrm{i}) \approx 0$.

Converting the concentration terms of the species to wt $\%$ scale, we have

$$
\frac{\mathrm{d}^{2} \mathrm{CuO}_{0.5}}{\mathrm{dt}}=-\mathrm{k}_{m} \cdot\left(\frac{\mathrm{A}}{\mathrm{V}}\right), \% \mathrm{CuO}_{n \text { s }}
$$

where ' $A$ ' and ' $V$ ' are the surface area and volume of the cylindrical crucible respectively, $k_{m}$ is the mass transfer coefficient of $\mathrm{CuO}_{0.5}$ in the slag phase.

Integrating equation (9) within the limits of ' 0 ' and ' $t$ ', we get:

$$
--\ln \left(\frac{\% \mathrm{CuO}_{05}^{\prime}}{\% \mathrm{CuO}_{05}^{\circ}}\right)=\left(\frac{2}{\mathrm{r}}\right) \cdot \mathrm{k}_{\mathrm{m}} \cdot \mathrm{t}
$$

where ' $r$ ' is the radius of the cylindrical crucible, $\% \mathrm{CuO}_{0 s}^{t}$ is the amount of copper oxide at any time ' $\mathrm{t}$ ' and $\% \mathrm{CuO}_{0}^{\circ}$ is the initial amount of copper oxide in the slag. A linear plot of the equation (10) indicates that the reaction mechanism is controlled by the diffusion of copper oxide to the slag/carbon interface. Figure 6 shows a linear fit of the left hand expression as a function of time.

Both the mechanisms yield a linear plot at all the temperatures since the final expressions for both the models are similar. However, the rate controlling mechanism cannot be ascertained solely by a linear fit of experimental data to the model equations. The influence of various other parameters such as temperature and stirring of the melt have to be analyzed in order to make a definite decision as to the most probable reduction mechanism.

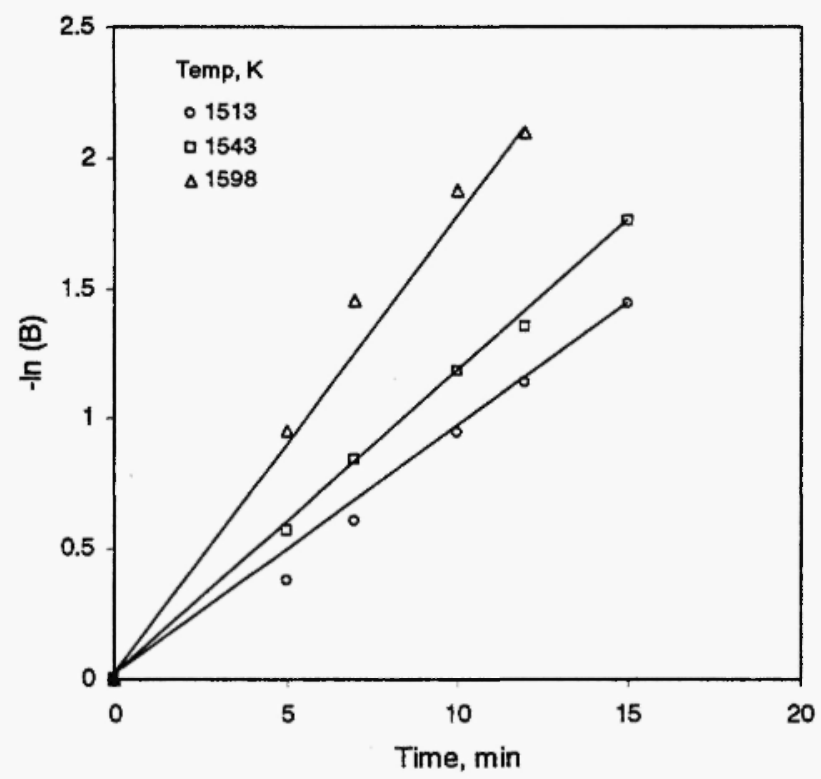

Fig. 6: Plot of the diffusion controlled model [Eqn. (9)], where $\mathrm{B}$ is given by $\left(\frac{\% \mathrm{CuO}_{\hat{0} .5}^{\mathrm{t}}}{\% \mathrm{CuO}_{0.5}^{\mathrm{o}}}\right)$

\section{E. Activation Energy}

In the present investigation, the rate of reduction of $\mathrm{CuO}_{0.5}$ was strongly influenced by temperature. The effect of temperature on rate constants follows the Arrhenius type of equation and is given by

$$
\mathrm{k}=\mathrm{k}_{\mathrm{o}} \mathrm{e}^{-\left(\frac{\mathrm{Q}}{\mathrm{RT}}\right)}
$$

where $k_{0}$ is termed as the frequency factor, $Q$ is the activation energy of the process, $R$ is the gas constant and $T$ is the absolute temperature. The activation energy of the reaction, $\mathrm{Q}$, can be obtained by plotting $\ln (\mathrm{k})$ as a function of $1 / T$. Figure 7 shows the plot of $\ln (k)$ vs $1 / T$ for both the chemical reaction and diffusion controlled 


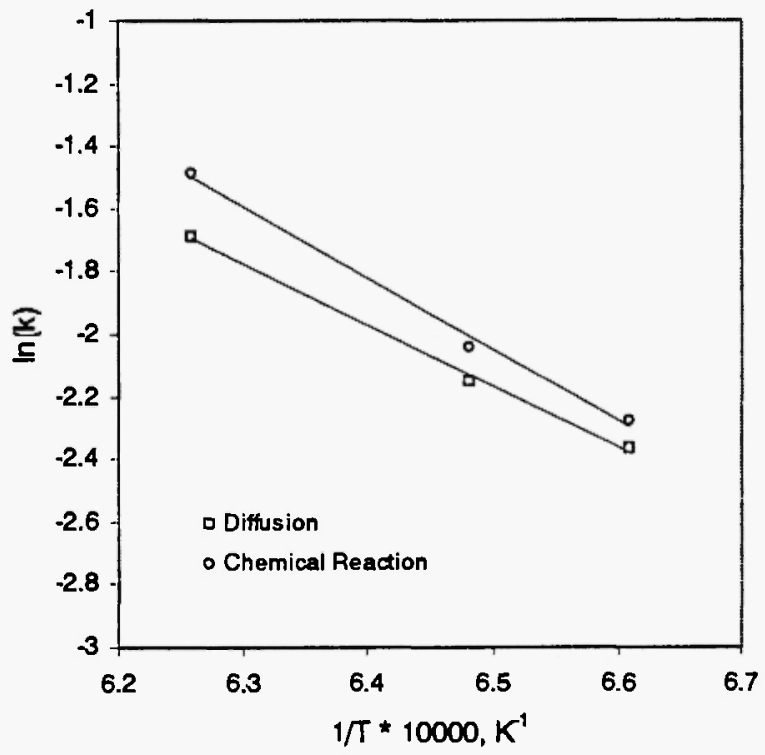

Fig. 7: Plot of $\ln (k)$ vs $1 / T$ for the two mechanism of the reduction process

reduction of copper oxide. Activation energy values of $188.4 \mathrm{~kJ} / \mathrm{mol}$ and $162.3 \mathrm{~kJ} / \mathrm{mol}$ were determined from the plots for the chemical reaction and diffusion controlled mechanisms respectively. The activation energy obtained for the chemical reaction controlled mechanism is of the same order as one would expect for a chemical reaction process.

Reduction of $\mathrm{Cu}_{2} \mathrm{O}$ from a slag $\left(40 \% \mathrm{SiO}_{2}, 40 \%\right.$ $\mathrm{CaO}$, and $20 \% \mathrm{Al}_{2} \mathrm{O}_{3}$ ) by $\mathrm{CO}$ was studied by Smirnov et. al., $/ 10 /$ in the temperature range of $1623-1723 \mathrm{~K}$. They obtained the activation energy of $171.5 \mathrm{~kJ} / \mathrm{mol}$ and they reported that the reaction was controlled by the indirect reduction by $\mathrm{CO}$ gas. The activation energy obtained in this study suggests that the mechanism of copper oxide reduction could be the Boudouard reaction catalyzed by the presence of $\mathrm{CuO}_{0.5}$ in the slag.

\section{DISCUSSION}

Figure 3 shows that stirring of the slag melt by argon did not affect the rate of copper oxide reduction at 1513 K. A similar effect was found at other temperatures as well. It can be stated that diffusion in the slag phase is not the rate controlling mechanism in the reduction of copper oxide.
The rate of reduction of copper oxide as a function of initial concentration of copper oxide in the slag (Fig. 4) was also analyzed using the chemical reaction model. Figure 8 shows the linear plot of the chemical reaction model given by equation (7) for both the slags. The slopes of the two lines are 0.094 and 0.084 corresponding to initial copper oxide content of $1.63 \%$ and $8.0 \%$ in the slags respectively. It can be seen that the slopes are identical within the experimental errors. The linearity of the plots in Fig. 8 and the plots in Fig. 3 confirm that the reduction of copper oxide in the slag was indeed controlled by the chemical reaction at the slag/graphite interface.

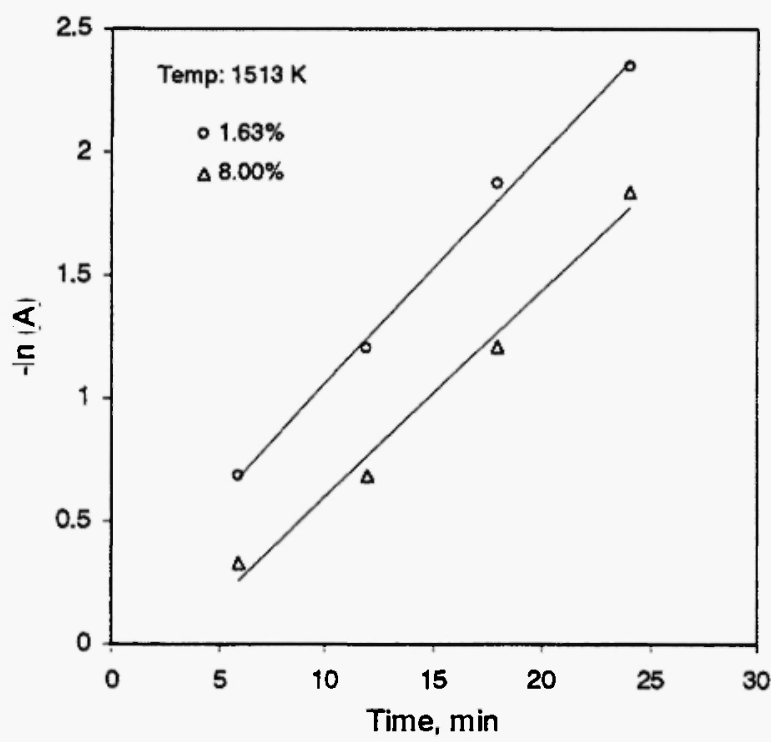

Fig. 8: Effect of initial concentration of copper oxide in slag on the reaction rate constant at $1513 \mathrm{~K}$, where $\mathrm{A}$ is given by $\left(\frac{\% \mathrm{CuO}_{0.5}^{\mathrm{t}}-\% \mathrm{CuO}_{0.5}^{\mathrm{e}}}{\% \mathrm{CuO}_{(.5}^{\mathrm{o}}-\% \mathrm{CuO}_{0.5}^{\mathrm{e}}}\right)$

The other possibilities for the rate controlling mechanism of copper oxide reduction could be the rate of nucleation of carbon monoxide at the reaction interface. In the experiments conducted in argon atmosphere, the bubbling of argon gas would have enhanced the chances of nucleation of carbon monoxide offering more sites. However, from Fig. 3 it can clearly be seen that bubbling argon through the melt did not improve the rate of reduction of copper oxide. Hence, 
the rate controlling step for the reduction of copper oxide from the slag melt by carbon could only be the chemical reaction at the reaction interface.

From the thermodynamic point of view all the reactions that are possible in the present system are listed in Table 1. Except for the reduction of $\mathrm{FeO}$ with $\mathrm{CO}$, all other reactions are thermodynamically possible in the temperature range of the present investigation. Analyzing the reactions in a sequence we find that essentially the reduction of $\mathrm{CuO}_{05}$ from the slag can take place either directly (by carbon) or indirectly (by $\mathrm{CO}$ ) or by metallic iron obtained from the reduction of $\mathrm{FeO}$ by carbon.

In an earlier study by the authors $/ 11 /$ on industrial slags, it was observed that more intense reducing conditions were required to reduce iron oxide. Experiments were performed at $1573 \mathrm{~K}$ and $5 \%$ carbon with and without a graphite lid covering the crucible. It was seen that in the experiments with the graphite disc, the iron recovery was $57.55 \%$ as compared to $28.97 \%$ in experiments without a lid. However, in both the cases no difference in the copper recovery was observed (85.04\% recovery with lid as compared to $84.09 \%$ without lid). Hence, it can be stated that reaction $3(\mathrm{c})$ in Table 1 was not the rate controlling step in the reduction of copper oxide.

Since reaction by $\mathrm{CO}$ gas is faster than the reaction with solid carbon, the Boudouard reaction was considered to control the reduction of copper oxide. The Gibbs energy data too suggest that the Boudouard reaction has much lower values than the reaction of copper oxide with $\mathrm{CO}$. Kinetics of the Boudouard reaction has been the focal point of many studies, especially pertaining to the reduction of iron oxide $/ 2-5 /$. Table 2 lists the activation energies for the systems where the Boudouard reaction was the rate controlling step. Values obtained from the present investigation are also included in the table for the sake of comparison.

Table 1

Standard Gibbs Energies of the Reactions Possible at the Operating Temperatures of this Study

\begin{tabular}{|c|c|c|c|}
\hline \multirow{2}{*}{ Reaction } & \multicolumn{3}{|c|}{$\Delta \mathrm{G}^{\circ}, \mathrm{kJ} / \mathrm{mol}$} \\
\cline { 2 - 4 } & $1513 \mathrm{~K}$ & $1543 \mathrm{~K}$ & $1598 \mathrm{~K}$ \\
\hline 1. Direct reduction with carbon & & & -201.84 \\
\hline $2\left(\mathrm{CuO}_{0.5}\right)+\mathrm{C}=2(\mathrm{Cu})+\mathrm{CO}$ & -189.24 & -193.67 & \\
\hline 2. Indirect reduction & & & -93.80 \\
(a) $2\left(\mathrm{CuO}_{0.5}\right)+\mathrm{CO}=2(\mathrm{Cu})+\mathrm{CO}_{2}$ & -96.06 & -95.27 & -108.11 \\
(b) $\mathrm{CO}_{2}+\mathrm{C}=2 \mathrm{CO}$ & -93.26 & -98.49 & \\
\hline 3. Reduction via iron & & & -92.67 \\
(a) $(\mathrm{FeO})+\mathrm{C}=(\mathrm{Fe})+\mathrm{CO}$ & -81.46 & -85.39 & +15.35 \\
(b) $(\mathrm{FeO})+\mathrm{CO}=(\mathrm{Fe})+\mathrm{CO}_{2}$ & +11.80 & +13.09 & -109.16 \\
(c) $\mathrm{Fe}+2(\mathrm{CuO} 0.5)=\mathrm{FeO}+2(\mathrm{Cu})$ & -107.78 & -108.28 & \\
\hline
\end{tabular}

Table 2

Comparison of Activation Energies for Copper Oxide Reduction and Boudouard Reactions

\begin{tabular}{|l|l|c|}
\hline \multicolumn{1}{|c|}{ Author } & \multicolumn{1}{|c|}{ Condition } & \multicolumn{1}{|c|}{$\begin{array}{c}\text { Activation Energy, } \\
\mathrm{kJ} / \mathrm{mol}\end{array}$} \\
\hline S. Ergun /12/ & $\begin{array}{l}\text { Kinetics of reaction of carbon with } \mathrm{CO}_{2} \text { in the temp. } \\
\text { range of } 973-1673 \mathrm{~K} \text { (Boudouard Reaction) }\end{array}$ & 246.8 \\
\hline V. M. Smirnov et al./10/ & $\begin{array}{l}\mathrm{Cu}_{2} \mathrm{O} \text { reduction from slag by CO in the temp. range of } \\
1623-1723 \mathrm{~K}\end{array}$ & 171.5 \\
\hline Present Study & $\begin{array}{l}\mathrm{CuO}_{0.5} \text { reduction from slag in temp. range of 1513- } \\
1598 \mathrm{~K}\end{array}$ & 188.4 \\
\hline
\end{tabular}


Smirnov et al. $/ 10 /$ have studied the reduction of copper oxide by $\mathrm{CO}$ in the temperature range of $1623-1723 \mathrm{~K}$.

They obtained the activation energy of $171.5 \mathrm{~kJ} / \mathrm{mol}$, which is in close agreement with the value obtained in the present investigation. Hence the rate controlling step in the reduction of copper oxide in the present case is considered to be the catalyzed Boudouard reaction.

\section{CONCLUSIONS}

Experiments were conducted on synthetic nonferrous slags to study the reduction kinetics of copper oxide by carbon. The effects of temperature, copper content in slag and stirring of the melt by argon on the reduction kinetics were studied. The reduction is rapid in the initial stages followed by a plateau region. The reduction follows first order kinetics with respect to the concentration of the reactant in the initial stages. Expressions for two theoretical models (chemical reaction and diffusion) have been derived to determine the reaction mechanism. Reduction of copper oxide $\left(\mathrm{CuO}_{0.5}\right)$ is controlled by the chemical reaction at the slag/graphite interface. The activation energy determined from the present investigation for the chemical reaction mechanism is $188.4 \mathrm{~kJ} / \mathrm{mol}$. The most probable reaction appears to be the indirect reduction of copper oxide by carbon monoxide gas. The activation energy obtained in this study suggests that the rate controlling step in the reduction of copper oxide was the Boudouard reaction catalyzed by the presence of copper oxide.

\section{ACKNOWLEDGEMENTS}

The authors are pleased to acknowledge the financial support for this research by the National Science
Foundation and ACIPCO.

\section{REFERENCES}

1. A. Yazawa, Y. Takeda, and S. Nakazawa, Copper 99-Cobre 99, Volume VI-Smelting, Technology Development, Process Modeling and Fundamentals, C. Diaz, C. Landolt and T. Utigard, eds., TMS, Warrendale, PA, 587-599, 1999.

2. M. Divakar, M. Görnerup, and A. K. Lahiri, High Temperature Materials and Processes, 20 (5-6), 393-401 (2001).

3. K. Seo, and R. J. Fruehan, ISIJ International, 40 (1), 7-15 (2000).

4. R. K. Paramguru, H. S. Ray, and P. Basu, Ironmaking and Steelmaking, 23 (4), 328-334 (1996).

5. A. Sato, G. Aragane, K. Kamihira, and S. Yoshimatsu, Transactions of Iron and Steel Institute of Japan, 27 (10), 789-796 (1987).

6. R. J. Pomfret and P. Grieveson, Canadian Metallurgical Quarterly, 22 (3), 287-299. (1983).

7. C. C. Banks and D. A. Harrison, Canadian Metallurgical Quarterhy, 14 (2), 183-190 (1975).

8. R. G. Reddy, Resources and Conservation, 9, 333 342 (1982).

9. J. M. Floyd and P. J. Mackey, IMM Symposium, Extraction Metallurgy, 1.M.M., London, 345-371 (1981).

10. V. M. Smirnov, B. A. Kukhtin, and G. A. Komlev, Soviet Non-ferrous Metals Research, 6 (2), 56-57 (1978).

11. V. L. Prabhu and R. G. Reddy, 2002, unpublished research.

12. S. Ergun, Journal of Physical Chemistry, 60 (4), 480-485 (1956). 
